\title{
1 Automatic determination of arsenate in drinking water by flow analysis with
}

2 dual membrane-based separation

3

4 Ruben Vera ${ }^{\mathrm{a}, \mathrm{b}}$, Yanlin Zhang ${ }^{\mathrm{a}}$, Clàudia Fontàs ${ }^{\mathrm{b}}$, M. Inês G.S. Almeida ${ }^{\mathrm{a}}$, Enriqueta Anticó ${ }^{\mathrm{b}}$,

5 Robert W. Cattrall ${ }^{\mathrm{a}}$, Spas D. Kolev ${ }^{\mathrm{a}, *}$

6 a School of Chemistry, The University of Melbourne, Victoria 3010, Australia

7 b Chemistry Department, University of Girona, C/ Maria Aurèlia Capmany, 69, 17003 Girona,

8 Spain.

9

10 Email addresses:

11 Ruben Vera - ruben.vech@gmail.com

12 Yanlin Zhang - yanlinz@unimelb.edu.au

13 Clàudia Fontàs - claudia.fontas@udg.edu

14 M. Inês G.S. Almeida - maria.gameirodesaalmeida@unimelb.edu.au

15 Enriqueta Anticó - enriqueta.antico@udg.edu

16 Robert W. Cattrall - r.cattrall@unimelb.edu.au

17 Spas D. Kolev-s.kolev@unimelb.edu.au

18

*Corresponding authors: S.D. Kolev: Tel. +61 38344 7931; E-mail address s.kolev@unimelb.edu.au; 


\section{Abstract}

21 The sequential application of a polymer inclusion membrane (PIM), composed of 22 poly(vinylidenefluoride-co-hexafluoropropylene) and the anionic extractant Aliquat 336, and a 23 microporous polytetrafluoroethylene (PTFE) gas-permeable membrane was utilized for the first 24 time to develop a flow analysis (FA) system, for the automatic determination of trace levels of 25 arsenate $(\mathrm{As}(\mathrm{V}))$ in drinking water as arsine. The system incorporated a flow-through extraction 26 cell for separation and preconcentration of arsenate and a gas-diffusion cell for the separation 27 of arsine prior to its spectrophotometric determination based on the discoloration of a potassium 28 permanganate solution. Under optimal conditions the FA system is characterized by a limit of 29 detection of $3.0 \mu \mathrm{g} \mathrm{L}^{-1} \mathrm{As}(\mathrm{V})$ and repeatability of $1.8 \%\left(\mathrm{n}=5,25 \mu \mathrm{g} \mathrm{\textrm {L } ^ { - 1 }} \mathrm{As}(\mathrm{V})\right)$ and $2.8 \%(\mathrm{n}=5$, $\left.3050 \mu \mathrm{g} \mathrm{L} \mathrm{L}^{-1} \mathrm{As}(\mathrm{V})\right)$. The newly developed FA method was successfully applied to the 31 determination of arsenate in drinking water samples in the $\mu \mathrm{g} \mathrm{L}^{-1}$ concentration range.

33 Keywords: drinking water; arsenate; flow analysis; polymer inclusion membrane (PIM); gas34 diffusion separation; hydride generation. 


\section{Introduction}

Arsenic is a naturally occurring toxic element, which is present in natural waters around the world (Villaescusa \& Bollinger, 2008). Inorganic arsenic species, such as arsenate (As(V)) and arsenite (As(III)), are the most common and toxic forms of arsenic found in aquatic systems (Vera, Fontas, \& Antico, 2017). Arsenic is considered a leading pollutant since it is often found at elevated levels in natural waters and long-term exposure to its forms have been associated with skin, lung, urinary tract, kidney, and liver cancer (Bissen \& Frimmel, 2003). Therefore, the World Health Organization (WHO) has set the guideline concentration for arsenic in drinking water at $10 \mu \mathrm{g} \mathrm{L}^{-1}(\mathrm{WHO}, 2011)$. It should be pointed out that arsenic in drinking water is present very often almost entirely as arsenate (As(V)) (Döker \& Y1lmaz, 2018; Komorowicz \& Barałkiewicz, 2016). The low regulated level of arsenic and its complex chemistry represent a challenge from an analytical point of view. Hence, a great number of highly sensitive analytical techniques have been developed and employed for the determination of arsenic in environmental samples, namely graphite furnace atomic absorption spectrometry (GFAAS) (Alves, Neri, Borges, Carvalho, \& Coelho, 2017), hydride generation atomic absorption spectrometry (HG-AAS) (Susko, Bloom, Neamtiu, Appleton, Surdu, Pop, et al., 2017), hydride generation atomic fluorescence spectrometry (HG-AFS) (Chen, Lai, Mao, Chen, \& Chen, 2017), inductively coupled plasma atomic emission spectrometry (ICP-AES) (Güell, Anticó, Kolev, Benavente, Salvadó, \& Fontàs, 2011), and inductively coupled plasma mass spectrometry (ICPMS) (Fontàs, Vera, Batalla, Kolev, \& Anticó, 2013; Vera, Fontas, \& Antico, 2017). These techniques provide the sensitivity required to directly measure arsenic concentrations in water samples at the $\mu \mathrm{g} \mathrm{L}^{-1}$ level. However, the techniques mentioned above require expensive equipment and highly trained laboratory technicians.

Flow injection analysis (FIA) is a technique suitable for performing analysis on-line in an automatic fashion and it is highly efficient in minimizing both reagent and sample consumption 
as well as the overall analysis time and associated costs (Cerda \& Estela, 2008; Valcarcel \& Luque de Castro, 1987). Different detection techniques have been successfully applied in FIA systems for the determination and speciation of arsenic (e.g., voltammetry (Fogg \& Bsebsu, 1981), amperometry (Farrell, Iles, \& Yuan, 1996; Rupasinghe, Cardwell, Cattrall, \& Kolev, 2009), chemiluminescence (Lomonte, Currell, Morrison, McKelvie, \& Kolev, 2007), or spectrophotometry (Boonjob, Miró, \& Kolev, 2013; Rupasinghe, Cardwell, Cattrall, Luque de Castro, \& Kolev, 2001; Rupasinghe, Cardwell, Cattrall, Potter, \& Kolev, 2004). A great number of spectrophotometric methods for arsenic are based on the method proposed by Johnson and Pilson (Johnson \& Pilson, 1972), in which an arsenomolybdenum blue complex is formed. However, this method is affected by severe interferences from silicate or phosphate, often present in arsenic samples, which impose serious limitations on the applicability of this method. To avoid the interference of phosphate and silicate, some authors have used anion-exchange columns to retain the interfering anions (Frenzel, Titzenthaler, \& Elbel, 1994; Narusawa, 1988) or optimized the molybdenum blue method to improve its selectivity for arsenate over phosphate, as reported by Dhar et al. (Dhar, Zheng, Rubenstone, \& Van Geen, 2004). Rupasinghe et al. (Rupasinghe, Cardwell, Cattrall, Potter, \& Kolev, 2004) and Toda et al. (Toda \& Ohba, 2005) have reported on the development of FIA systems based on hydride generation where arsenic is converted into arsine followed by bleaching an oxidant acceptor solution containing $\mathrm{KMnO}_{4}$. The concentration of arsenic in many water samples is at trace level and preconcentration is often required.

Membrane-based extraction procedures involving liquid membranes have emerged as promising alternatives to ion-exchange based separation and preconcentration where retention and stripping of the analyte take place sequentially. In liquid membrane-based separation the extraction and back-extraction of the analyte from a donor aqueous stream into an acceptor aqueous stream occur simultaneously. Supported liquid membranes (SLMs), which are 
considered as the most frequently used type of liquid membranes at present, have been used successfully in the determination of arsenate in drinking water (Kamyabi \& Aghaei, 2016). However, in this type of membranes the membrane liquid phase, consisting of an extractant and diluent, is retained in the micrometre size pores of a hydrophobic polymeric membrane and this leads to leaching of the membrane liquid phase into the donor and acceptor aqueous phases, thus causing potential deterioration in the performance of the SLM (Almeida, Cattrall, \& Kolev, 2017).

Recently, polymer inclusion membranes (PIMs) have been shown to have a better stability than SLMs (Almeida, Cattrall, \& Kolev, 2012). PIMs are cast from a solution of a base-polymer, extractant and in some cases plasticizer or modifier in a suitable solvent (Almeida, Cattrall, \& Kolev, 2012; Nghiem, Mornane, Potter, Perera, Cattrall, \& Kolev, 2006). The reason behind their superior stability compared to SLMs stems from the fact that the membrane liquid phase of PIMs (i.e., extractant and plasticizer/modifier) is retained between the entangled polymer chains of the base-polymer, thus minimizing significantly its leaching to the adjacent aqueous solutions. The base-polymer provides mechanical strength to the PIM, while the extractant (carrier) is responsible for the extraction/transport of the chemical species of interest. The plasticizer or modifier are often added to the PIM composition to provide elasticity or increased solubility of the extracted species in the membrane liquid phase, respectively (Nghiem, Mornane, Potter, Perera, Cattrall, \& Kolev, 2006). PIMs have been successfully employed in flow analysis (FA) systems for the on-line separation and preconcentration of $\mathrm{Zn}$ (II) (L. L. Zhang, Cattrall, Ashokkumar, \& Kolev, 2012; L. L. Zhang, Cattrall, \& Kolev, 2011), orthophosphate (Nagul, Fontàs, McKelvie, Cattrall, \& Kolev, 2013) and vanadium(V) (Yaftian, Almeida, Cattrall, \& Kolev, 2018).

The present paper reports on the development of a spectrophotometric FA system implementing on-line preconcentration of arsenate using a PIM consisting of poly(vinylidene 
111 fluoride-co-hexafluoropropylene) (PVDF-HFP) and Aliquat 336 followed by on-line

112 generation of arsine which diffuses across a gas-permeable membrane into a $\mathrm{KMnO}_{4}$ solution

113 causing its discoloration. To the best of our knowledge this is the first use of a PIM in an FA

114 system for the determination of arsenate in drinking waters at low $\mu \mathrm{g} \mathrm{L}^{-1}$ levels and the first 115 coupling of on-line membrane-based extractive separation with on-line membrane-based gas116 diffusion separation.

\section{Experimental}

\subsection{Reagents and solutions}

All reagents and solvents used in this study were of analytical reagent grade. The polymers 121 PVDF-HFP (Aldrich, USA) and poly(vinyl chloride) PVC (Fluka, Italy), the extractant Aliquat 122336 (Aldrich, USA), and the modifier 1-tetradecanol (Aldrich, USA) were used as constituents 123 of the PIMs studied. Tetrahydrofuran (THF) without a stabilizer, purchased from VWR 124 (Australia), was used as the membrane casting solvent. The acceptor solution used in the PIM125 based separation step contained $0.1 \mathrm{~mol} \mathrm{~L}^{-1} \mathrm{NaCl}$ (Chem-Supply, Australia) as the stripping 126 reagent for arsenate. The reduction of $\mathrm{As}(\mathrm{V})$ to $\mathrm{As}(\mathrm{III})$ was conducted using a reductant solution 127 composed of $4 \mathrm{~mol} \mathrm{~L}^{-1} \mathrm{HCl}(32 \%$, RCI Labscan, Thailand), 1\% (w/v) KI (Aldrich, USA), and $1280.5 \%(\mathrm{w} / \mathrm{v})$ ascorbic acid (AA) (Ajax Finechem, Australia). The sodium borohydride reagent stream used for arsine generation contained $0.5 \%(\mathrm{w} / \mathrm{v}) \mathrm{NaBH}_{4}$ and $0.05 \mathrm{~mol} \mathrm{~L}^{-1} \mathrm{NaOH}$ (Chem-

130 Supply, Australia). Arsine was absorbed and oxidized in the gas-diffusion acceptor stream 131 containing $0.2 \mathrm{mmol} \mathrm{L}^{-1} \mathrm{KMnO}_{4}$ (Chem-Supply, Australia) and $0.05 \mathrm{~mol} \mathrm{~L}^{-1} \mathrm{NaOH}$ (Chem132 Supply, Australia).

133 The interference studies were performed with working solutions prepared by dilution of 134 stock solutions containing $500 \mathrm{mg} \mathrm{L}^{-1} \mathrm{H}_{2} \mathrm{PO}_{4}^{-}, \mathrm{Cl}^{-}, \mathrm{NO}_{3}^{-}, \mathrm{HCO}_{3}^{-}$, or $\mathrm{SO}_{4}{ }^{2-}$. These stock 135 solutions were prepared by dissolving $\mathrm{Na}_{2} \mathrm{HPO}_{4}$ (BDH, Australia), $\mathrm{NaCl}, \mathrm{NaNO}_{3}$ (Ajax, 
136 Australia), $\mathrm{NaHCO}_{3}$ (Chem-Supply, Australia), or $\mathrm{Na}_{2} \mathrm{SO}_{4}$ (Chem-Supply, Australia) in

137 ultrapure water $(\geq 18.2 \mathrm{M} \Omega \mathrm{cm}$, Millipore, Synergy 185, France), used in the preparation of all 138 aqueous solutions.

\subsection{Instrumentation}

On-line spectrophotometric detection was conducted with a Pharmacia Novaspec II UV-

142 Vis spectrophotometer (Pharmacia Biotech, Sweden) fitted with a flow-through cell made of 143 quartz (10 mm optical path length, Starna, UK). The spectrophotometer was interfaced with a 144 PowerChrom 280 (Model ER280) data recording system linked to a PC and run by the Chart 145 software package (eDAQ, Australia).

146 The PIMs thickness was measured using an optical microscope (Model LH50A, Olympus, 147 Japan) with a calibrated lens (Carton Optical Ind., Japan).

148 For method validation the samples were also analysed after off-line pre-reduction with a 149 solution containing a mixture of $1 \%(\mathrm{w} / \mathrm{v}) \mathrm{KI}$ and $0.5 \%(\mathrm{w} / \mathrm{v})$ ascorbic acid by inductively 150 coupled plasma optical emission spectrometry (ICP-OES, Model Optima 4300 DV, Perkin151 Elmer) incorporating a home-made hydride generation unit.

\subsection{Flow Analysis (FA) manifold}

The FA manifold developed in the present study for arsenate preconcentration, separation 155 and detection involving hydride generation is depicted in Figure 1. 
156

157 Figure 1. Schematic of the FA manifold. P1-P3: peristaltic pumps; R1: gas-diffusion acceptor stream (0.2 mM M KMnO $4,0.05 \mathrm{M} \mathrm{NaOH}) ; \mathrm{R} 2: \mathrm{NaBH}_{4}$ stream $\left(0.5 \%\right.$ (w/v) $\mathrm{NaBH}_{4}$, $\left.0.05 \mathrm{~mol} \mathrm{~L}^{-1} \mathrm{NaOH}\right)$; R3: reductant stream (4 M HCl, 1\% (w/v) KI, 0.5\% (w/v) ascorbic acid); R4: PIM acceptor stream (0.1 M NaCl); R5: PIM donor stream; RC: reaction coil; IV: injection valve; GDC: gas-diffusion cell; PIM: polymer inclusion membrane.

The system consisted of 3 four-channel peristaltic pumps, i.e., Pump 1 and Pump 2 (Model 164 VS4, Watson Marlow Alitea, Sweden) and Pump 3 (Gilson Minipuls-3, France). All the pumps were fitted with Tygon tubing of suitable internal diameter (TACS, USA).

166 Polytetrafluoroethylene (PTFE) tubing of $0.5 \mathrm{~mm}$ i.d. was used throughout the manifold, except 167 for the gas-diffusion acceptor stream outlet tubing, which was of $3 \mathrm{~m}$ length and $0.3 \mathrm{~mm}$ i.d. to 168 provide sufficient back-pressure. The latter was required to prevent the diffusion of $\mathrm{H}_{2}$, 169 generated by the decomposition of $\mathrm{NaBH}_{4}$, across the hydrophobic microporous membranes 170 and the filter paper of the gas-diffusion cell (GDC, Fig. 2a) into Stream R1 where it would have 171 interfered with the analytical measurements. The following hydrophobic microporous 
membranes were used in the present study: Durapore ${ }^{\circledR}$ and SureVent ${ }^{\circledR}$ membranes (Merck Millipore, USA), PTFE membranes (Reece, Australia), and polypropylene membranes (Chemplex, Zimbabwe). The flow rates of all streams were measured gravimetrically by weighing the mass of water of known temperature pumped through the corresponding tubing over a 5 min period. On-line preconcentration of arsenate was performed using a home-made extraction cell similar to the one described previously by us (L. L. Zhang, Cattrall, \& Kolev, 2011), which consisted of two Perspex blocks (150 mm length, $30 \mathrm{~mm}$ width and $15 \mathrm{~mm}$ height, each) clamped together by stainless steel screws. The two channels of the extraction cell were serpentine shaped and were 157, 1 and $0.25 \mathrm{~mm}$ in length, width and depth, respectively. Arsine was separated in a homemade GDC (Figure 2) made of Perspex and identical to the one used previously by us (Y. Zhang, Miró, \& Kolev, 2015) where arsine diffused from the gas-diffusion donor stream (Streams R2+R3+R4, Figure 1) across an assembly of a filter paper disc (No. 54, Whatman, Britain) sandwiched between two hydrophobic microporous membranes (Figure 2a) into the gas-diffusion acceptor stream (Stream R1). The filter paper was used as a physical support for the hydrophobic membranes, which otherwise could have stretched as a result of the pressure difference between the two channels of the GDC (Figure 2a) thus changing the channels' volume and impacting negatively on repeatability. The shape of the two channels of identical width and length (Figure 2b), i.e., $1.8 \mathrm{~mm}$ and $100 \mathrm{~mm}$, respectively, ensured efficient mixing of the gas-diffusion donor and acceptor streams which improved the generation, transmembrane transfer and oxidation of arsine in the gas-diffusion acceptor stream (Stream R1) (Y. Zhang, Miró, \& Kolev, 2015). The depths of the acceptor and the donor channels were 0.5 and $6 \mathrm{~mm}$, respectively, and the corresponding volumes were $90 \mu \mathrm{L}$ and $1080 \mu \mathrm{L}$, respectively. This volume difference coupled with appropriately selected flow rates of Streams R1 - R4 allowed a degree of preconcentration of arsenic as arsine in the gas-diffusion acceptor stream (Stream R1). 
(a)

197

198

199

200

201

202

203

204

205

206

207

208

209

210

211

212

213

214

215

216

217 (b)

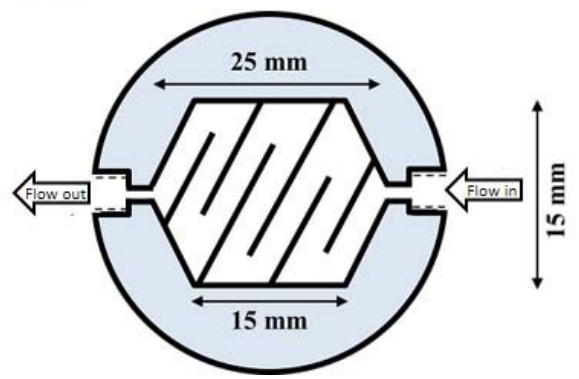

Figure 2. Schematic of the GDC used in the on-line separation of arsine. (a) Cross-section (donor and acceptor channels depths - 6 and $0.5 \mathrm{~mm}$, respectively) and (b) top view of one of the halves of the GDC.

\subsection{FA procedure}

The standard/sample solution (Stream R5, Figure 1) was propelled for a predetermined period of time through the donor channel of the extraction cell where a PIM separated the sample (donor) stream (Stream R5) from the acceptor stream (Stream R4). The acceptor stream was stopped for a predetermined period of stop-flow time during the sample passage through the donor channel of the extraction cell to allow preconcentration of arsenate in the static acceptor solution located in the acceptor channel of the cell. At the end of the stop-flow time, the acceptor stream (R4) was re-started and arsenate was reduced to arsenite by merging the acceptor stream of the extraction cell (R4) with a reagent stream (R3) containing $\mathrm{HCl}$, $\mathrm{KI}$ and ascorbic acid. Subsequently, arsine was generated by merging the combined R4+R3 stream with a sodium borohydride stream (R2). The generated arsine in the combined stream $\mathrm{R} 4+\mathrm{R} 3+\mathrm{R} 2$ diffused across the hydrophobic membrane of the GDC into the acceptor solution of the gas-diffusion cell (R1) where it was oxidised by $\mathrm{KMnO}_{4}$ resulting in a decrease in the $\mathrm{KMnO}_{4}$ absorbance, monitored continuously at $528 \mathrm{~nm}$ in the spectrophotometric measuring cell of the manifold. In all measurements, the analytical signal recorded was the maximum decrease in $\mathrm{KMnO}_{4}$ absorbance relative to the baseline level. 


\subsection{Optimization of the FA method}

The optimization of the reaction coil (RC) length (Figure 1) and the flow rate of Stream

221 R1 and the selection of the most appropriate hydrophobic gas-diffusion membrane were carried 222 out in a FA system similar to the one shown in Figure 1 where the extraction cell was replaced 223 with an injection valve with a $500 \mu \mathrm{L}$ sample loop. The standards injected in these experiments 224 contained $1000 \mu \mathrm{g} \mathrm{L}{ }^{-1} \mathrm{As}(\mathrm{V})$.

The suitability of different PIM compositions was tested in the FA manifold shown in Figure 1 using a stop-flow procedure in which $5 \mathrm{~mL}$ of a $1000 \mu \mathrm{g} \mathrm{L}^{-1} \mathrm{As}(\mathrm{V})$ standard solution were propelled at a flow rate of $0.2 \mathrm{~mL} \mathrm{~min}{ }^{-1}$ through the donor channel of the extraction cell. The influence of the stop-flow time and the flow rate of Stream R5 was studied by propelling a standard solution containing $500 \mu \mathrm{g} \mathrm{L}^{-1} \mathrm{As}(\mathrm{V})$ through the donor channel of the extraction cell.

\subsection{PIM preparation}

PVC-based PIMs containing 70\% (w/w) PVC and 30\% (w/w) Aliquat 336 were prepared by dissolving $180 \mathrm{mg}$ of Aliquat $336 \mathrm{in} 18 \mathrm{~mL}$ of THF, followed by slow addition of $420 \mathrm{mg}$ of PVC into the casting solution, which was constantly stirred to avoid aggregation of the polymer. Finally, the resulting mixture was poured into a $16.5 \mathrm{~cm}$ in diameter glass ring sitting on a flat glass plate. The ring was covered with filter paper and a watch glass to slow down the evaporation of THF in the next $15 \mathrm{~h}$ after which the resulting PIM was carefully peeled from

239 the glass plate (Fontàs, Vera, Batalla, Kolev, \& Anticó, 2013; Nagul, Fontàs, McKelvie, Cattrall, 240 \& Kolev, 2013).

PIMs containing 1-tetradecanol as a modifier were also prepared by the casting method 
243 dissolved in the casting solution together with $420 \mathrm{mg}$ of PVC and the corresponding PIMs

244 contained 70\% (w/w) PVC, 20\% (w/w) Aliquat 336 and 10\% (w/w) 1-tetradecanol.

245 The PVDF-HFP-based membranes were prepared following the procedure described by

246 O'Bryan et al. (O'Bryan, Cattrall, Truong, Kyratzis, \& Kolev, 2016). In this method, $700 \mathrm{mg}$ of 247 PVDF-HFP and $300 \mathrm{mg}$ of Aliquat 336 were dissolved in $8 \mathrm{~mL}$ of THF at $50{ }^{\circ} \mathrm{C}$ and the mixture

248 was mechanically stirred until the complete dissolution of all PIM components. The casting

249 solution was then spread onto a glass plate using a casting knife with $0.5 \mathrm{~mm}$ depth setting 250 (O'Bryan, Cattrall, Truong, Kyratzis, \& Kolev, 2016). The glass plate was covered with an 251 aluminium tray to allow the slow evaporation of THF in the next $48 \mathrm{~h}$ after which the membrane 252 was peeled from the glass plate.

253

254

255

256

257

258

259

260

261

262

263

264

265

\subsection{Interference studies}

The effect of common anions in appropriately selected concentration ranges (i.e., $0.15 \mathrm{mg} \mathrm{L}^{-1}-140 \mathrm{mg} \mathrm{L}^{-1}$ in the case of $\mathrm{H}_{2} \mathrm{PO}_{4}^{-}$and $1.0 \mathrm{mg} \mathrm{L}^{-1}-40 \mathrm{mg} \mathrm{L}^{-1}$ in the case of $\mathrm{NO}_{3}^{-}$, $\mathrm{Cl}^{-}, \mathrm{HCO}_{3}{ }^{-}$, and $\left.\mathrm{SO}_{4}{ }^{2-}\right)$ on the analytical signal for a $0.05 \mathrm{mg} \mathrm{L}^{-1}\left(0.67 \mu \mathrm{mol} \mathrm{L}{ }^{-1}\right) \mathrm{As}(\mathrm{V})$ standard was studied.

\subsection{Sample analysis}

Spiked with arsenate at the $\mu \mathrm{g} \mathrm{L}^{-1}$ level tap and mineral water samples were analysed by both the newly developed FA method and ICP-OES. The tap water was obtained from Melbourne's public water supply, and the commercial mineral waters analysed were: Voss Still Water (Norway), Woolworths Mountain Spring Water (Australia) and Icelandic Spring Water (Iceland). All samples were analysed by the standard addition method, involving at least 3 standard additions, and the measurements were performed in triplicate (unless otherwise stated). 


\section{Results and discussion}

\subsection{Optimization of the FA system parameters}

The optimization range and the initial and optimal values for each of the design and

271 operational parameters of the newly developed FA system investigated in this study are 272 summarized in Table 1 in the order in which the optimization was done. The initial value of a 273 parameter was the value used in the experiments prior to the optimization of this parameter. 274 The compositions of the Streams R1 $\left(0.2 \mathrm{mmol} \mathrm{L}^{-1} \mathrm{KMnO}_{4}\right.$ and $\left.0.05 \mathrm{~mol} \mathrm{~L}^{-1} \mathrm{NaOH}\right), \mathrm{R} 2(0.5 \%$ 275 (w/v) $\mathrm{NaBH}_{4}$ and $\left.0.05 \mathrm{~mol} \mathrm{~L}^{-1} \mathrm{NaOH}\right)$ and $\mathrm{R} 3(4 \mathrm{M} \mathrm{HCl}+1 \%(\mathrm{w} / \mathrm{v}) \mathrm{KI}+0.5 \%(\mathrm{w} / \mathrm{v})$ ascorbic 276 acid) were selected on the basis of the results obtained in an earlier study involving the 277 determination of arsenic by a gas-diffusion/hydride generation approach (Y. Zhang, Miró, \& 278 Kolev, 2015). To simplify the operation of the FA system, Streams R2, R3 and R4 were kept 279 at the same flow rate of $0.12 \mathrm{~mL} \mathrm{~min}^{-1}$.

280

281 Table 1. Optimization of the FA system for the determination of As(V).

\begin{tabular}{lccc}
\hline \multicolumn{1}{c}{ Parameter } & Range studied & Initial value & Optimal value \\
\hline Reaction coil length $(\mathrm{m})$ & $0-3.00$ & 2.50 & 0.25 \\
Stream R1 flow rate $\left(\mathrm{mL} \mathrm{min}^{-1}\right)$ & $0.06-0.46$ & 0.24 & 0.06 \\
Gas-diffusion membrane & Polypropylene & & \\
& Durapore ${ }^{\circledR}$ & & \\
& SureVent ${ }^{\circledR}$ & & \\
& PTFE & & \\
PIM composition $(\%(\mathrm{w} / \mathrm{w}))$ & 70 PVC, $30 \mathrm{~A} 336$ &
\end{tabular}

70 PVC, 20 A336, 10 1-TD

70 PVDF-HFP, 30 

$[\mathrm{NaCl}]$ in $\mathrm{R} 4\left(\mathrm{~mol} \mathrm{~L}^{-1}\right)$
$0.05-0.2$
0.1
0.1
Stream R5 flow rate $\left(\mathrm{mL} \mathrm{min}^{-1}\right)$
$0.2-3.0$
0.2
2.5
Stop-flow time of the acceptor
stream of the extraction cell ( $\mathrm{min})$

$$
2-30
$$

A336 - Aliquat 336, 1-TD - 1-tetradecanol

\subsubsection{Effect of the reaction coil length, flow rate of Stream $R 1$ and type of the gas-diffusion} membrane

As mentioned earlier, the influence of these parameters was studied in an FA system, similar to the one shown in Figure 1, where the extraction cell was replaced with an injection valve with a $500 \mu \mathrm{L}$ sample loop.

The length of the reaction coil (RC, Figure 1), where Streams R3 and R4 were merged, was varied between $0 \mathrm{~m}$ (i.e., no reaction coil) and $3 \mathrm{~m}$. The $\mathrm{RC}$ length affected both the efficiency of mixing between the two streams mentioned above and the dispersion of arsenic in the donor stream of the gas-diffusion cell. As expected, a longer RC enhanced arsenic dispersion which offset any increase in the analytical signal due to better mixing between

294 Streams R3 and R4. The highest analytical signal was obtained when the length of the RC was $2950.25 \mathrm{~m}$ and this length of the RC was used in the subsequent experiments. The percentage of $\mathrm{As}(\mathrm{V})$ converted into As(III) under these experimental conditions was calculated as equal to $70 \%$, by comparing the analytical signals for standards containing $1000 \mu \mathrm{g} \mathrm{L}-1$ of either As(III) or $\operatorname{As}(\mathrm{V})$.

As expected, higher analytical signals were recorded when lower flow rates of Stream R1 were used due to the fact that arsine generated in the RC was transferred into a smaller volume of the $\mathrm{KMnO}_{4}$ acceptor solution of Stream R1. Experiments involving stopping Stream R1 
during arsine generation were also conducted but they resulted in unstable baseline due to the transfer of greater and irreproducible amounts of $\mathrm{H}_{2}$ into the static $\mathrm{KMnO}_{4}$ solution located in

304 the acceptor channel of the gas-diffusion cell (Figure 1). In addition, no enhancement in the 305 analytical signal was observed. Hence, $0.06 \mathrm{~mL} \mathrm{~min}^{-1}$ was selected as the optimal flow rate of 306 Stream R1 since this was the lowest flow rate that could be reproducibly maintained by 307 Peristaltic pump P1.

308 Four different hydrophobic microporous membranes (i.e., Durapore ${ }^{\circledR}$, SureVent ${ }^{\circledR}$, PTFE, 309 and polypropylene membranes) were compared with respect to their permeability to arsine, 310 which was estimated on the basis of the corresponding analytical signal values. In each case the 311 two channels of the gas-diffusion cell were separated by two membrane layers and a filter paper 312 disc sandwiched between them. When the Durapore ${ }^{\circledR}$ membrane was tested a rapid formation 313 of a brown stain on both membrane surfaces was observed due to manganese dioxide formation, 314 and for this reason this membrane was discarded. The average analytical signals based on 10 315 replicate measurements of a $1000 \mu \mathrm{g} \mathrm{L}^{-1} \mathrm{As}(\mathrm{V})$ standard for the remaining three membranes 316 were $0.081 \pm 0.004$ for the polyprolylene membrane, $0.101 \pm 0.004$ for the PTFE membrane, 317 and $0.102 \pm 0.004$ for the SureVent ${ }^{\circledR}$ membrane. Although no significant difference between 318 the last two membranes was obtained, the baseline was not very stable when using the PTFE 319 membrane, possibly due to its malleability. SureVent ${ }^{\circledR}$ membrane was selected for further use 320 because it was slightly thicker and more robust than the PTFE membrane and no issues with 321 baseline stability were observed.

\subsubsection{Effect of the PIM and the compositions of Stream R4}

324 Fontàs et al. (Fontàs, Vera, Batalla, Kolev, \& Anticó, 2013), reported on the successful use 325 of a PIM composed of the base-polymer PVC and the carrier Aliquat 336 for the 326 preconcentration of arsenate in groundwater samples. The optimal composition of this PIM, i.e., 
$70 \%(\mathrm{w} / \mathrm{w})$ PVC and 30\% (w/w) Aliquat 336, was determined in a previous study by the same research team (Güell, Anticó, Kolev, Benavente, Salvadó, \& Fontàs, 2011). In this and other studies (Güell, Anticó, Kolev, Benavente, Salvadó, \& Fontàs, 2011; Güell, Fontàs, Anticó, Salvadó, Crespo, \& Velizarov, 2011) $0.1 \mathrm{M} \mathrm{NaCl}$ was found to be the most suitable receiving solution for arsenate. The separation of arsenate using an Aliquat 336-based PIM involves the extraction of the $\mathrm{HAsO}_{4}{ }^{2-}$ anion from the sample solution into the PIM, followed by the diffusion of the corresponding adduct of this anion with the quaternary alkylammonium cation of Aliquat $336\left(\mathrm{~A}^{+}\right)$across the membrane and the back-extraction of $\mathrm{HAsO}_{4}{ }^{2-}$ into the acceptor solution containing $\mathrm{NaCl}$ as the stripping reagent (Güell, Anticó, Kolev, Benavente, Salvadó, \& Fontàs, 2011). The equilibrium, described by Eq. (1), is shifted to the right (extraction into the PIM) at the sample solution/PIM interface and to the left (back-extraction into the acceptor solution) at the PIM/acceptor solution interface.

$$
\mathrm{HAsO}_{4}{ }^{2-}+2\left(\mathrm{~A}^{+} \mathrm{Cl}^{-}\right) \mathrm{PIM} \leftrightarrows\left[\left(\mathrm{A}^{+}\right)_{2} \mathrm{HAsO}_{4}{ }^{2-}\right] \mathrm{PIM}+2 \mathrm{Cl}^{-}
$$

The PIM and the receiving solution, mentioned above, were initially used in the newly developed FA system for the on-line preconcentration of As(V). However, the analytical signals obtained in 3 consecutive measurements of a $1000 \mu \mathrm{g} \mathrm{L} \mathrm{L}^{-1} \mathrm{As}(\mathrm{V})$ standard $(0.09,0.08,0.03)$ were relatively low. The poor repeatability was most likely due to the leaching of the PIM liquid phase consisting of Aliquat 336 into the adjacent aqueous phases. Therefore, other PIM compositions were explored.

One of them was the composition reported by Cho et al. (Cho, Xu, Cattrall, \& Kolev, 2011) for the extraction of thiocyanate from weakly alkaline aqueous solutions which consisted of 20\% (w/w) Aliquat 336, 10\% (w/w) 1-tetradecanol and 70\% (w/w) PVC. This study demonstrated that the addition of a modifier (e.g., 1-tetradecanol) of a very low water solubility reduced significantly the leaching of the PIM liquid phase. However, the analytical signal achieved with this PIM composition (i.e., 0.041, 0.017, 0.023), though higher than the one for 
the PIM composed of only $70 \%(\mathrm{w} / \mathrm{w})$ PVC and 30\% (w/w) Aliquat, also showed poor repeatability.

O’Bryan et al. (O'Bryan, Cattrall, Truong, Kyratzis, \& Kolev, 2016) demonstrated that PVDF-HFP-based PIMs containing 30\% (w/w) Aliquat 336 and 70\% (w/w) PVDF-HFP exhibited a significantly higher extraction and back-extraction rates for thiocyanate and higher stability compared to PVC-based PIMs containing the same concentration of liquid phase. This PIM provided much higher analytical signal (i.e., 0.173, 0.173, 0.172) and excellent repeatability and therefore was used in the subsequent experiments.

The concentration of $\mathrm{NaCl}$ in Stream $\mathrm{R} 4$ was varied between 0.05 and $0.20 \mathrm{~mol} \mathrm{~L}^{-1}$. As expected, the analytical signal increased with increasing the $\mathrm{NaCl}$ concentration up to $0.1 \mathrm{~mol} \mathrm{~L}^{-1}$ after which no further signal enhancement was observed. Therefore, $0.1 \mathrm{~mol} \mathrm{~L}^{-1}$ was selected as the optimal $\mathrm{NaCl}$ concentration in Stream $\mathrm{R} 4$.

\subsubsection{Effect of the flow rate of Stream $R 5$ and the stop-flow time for Stream R4}

It can be expected that the analytical signal will depend heavily on both the flow rate of

367 Stream R5 and the stop-flow time (i.e., duration of the sample flow through the extraction cell)

368 because these two parameters determine the sample volume and its contact time with the PIM.

369 The individual effects of these two parameters on the analytical signal are not independent of 370 each other and for this reason their combined effect was studied and the results are presented 371 in Figure 3. It was observed that, independently of the flow rate of Stream R5, the analytical 372 signal increased rapidly with increasing the stop-flow time up to $15 \mathrm{~min}$ and then it started 373 gradually to level off. Also, it was observed that independently of the stop-flow time, the 374 analytical signal increased with increasing the flow rate of Stream R5 up to $2.5 \mathrm{~mL} \mathrm{~min}{ }^{-1}$ after 375 which it started decreasing. Therefore, $2.5 \mathrm{~mL} \mathrm{~min}^{-1}$ was selected as the optimal flow rate. The 376 analytical signal did not increase significantly for stop-flow times greater than 15 min (e.g., an 
increase in the stop-flow time from 15 to 25 min resulted in only $10 \%$ increase in the analytical signal) and this value was selected as the optimal stop-flow time.

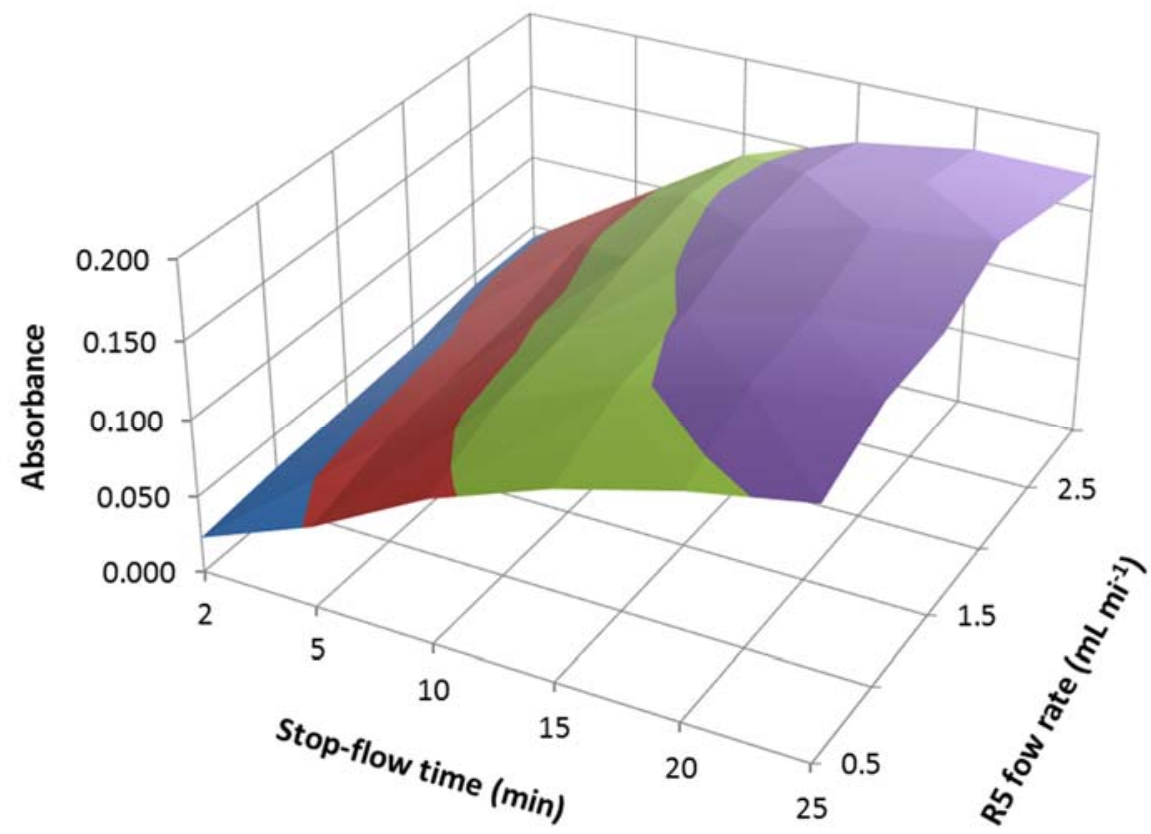

380 Figure 3. Influence of the stop-flow flow time and the flow rate of Stream R5 on the analytical 381 signal for a $500 \mu \mathrm{g} \mathrm{L} \mathrm{L}^{-1} \mathrm{As}(\mathrm{V})$ standard.

\subsection{Interference studies}

The presence of common anions in natural water (e.g., $\mathrm{H}_{2} \mathrm{PO}_{4}^{-}, \mathrm{Cl}^{-}, \mathrm{NO}_{3}{ }^{-}, \mathrm{HCO}_{3}{ }^{-}$, and $\mathrm{SO}_{4}{ }^{2-}$ ) which can compete with the extraction of arsenate (Fontàs, Vera, Batalla, Kolev, \& Anticó, 2013), makes it necessary to investigate their potential interference. No interference effects associated with these anions were expected in the arsine generation, trans-membrane transport and detection steps. Figure 4 shows the normalized analytical signal as a function of

389 the logarithm of the concentration ratio between each one of the anions mentioned above and 390 arsenate. The normalized analytical signal was calculated as a fraction of the analytical signal 391 in the absence of interfering ions. Interference effects were observed only when the concentration of the interfering ions exceeded by 2 orders of magnitude the arsenate 
394 addition method should be used.

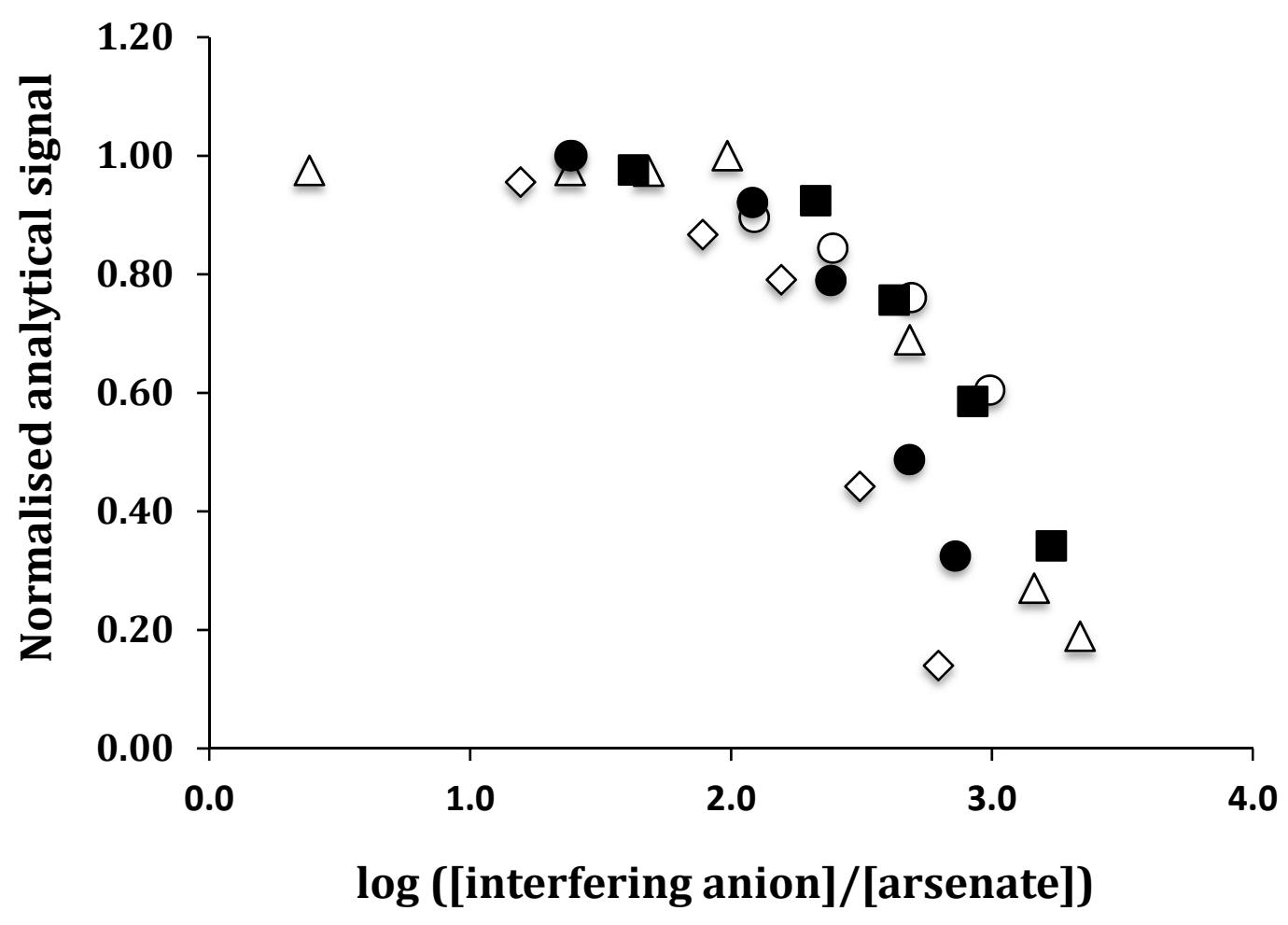

Figure 4. Effect of the concentration of $\mathrm{H}_{2} \mathrm{PO}_{4}{ }^{-}(\triangle), \mathrm{NO}_{3}^{-}(\bullet), \mathrm{SO}_{4}{ }^{2-}(\diamond), \mathrm{HCO}_{3}{ }^{-}(\bigcirc), \mathrm{Cl}^{-}$

(घ) on the normalised analytical signal for a $0.67 \mu \mathrm{mol} \mathrm{L}^{-1}\left(50 \mu \mathrm{g} \mathrm{L}^{-1}\right) \mathrm{As}(\mathrm{V})$ standard.

\subsection{Analytical figures of merit}

Under optimal conditions (Table 1) the newly developed FA method is characterised by a

401 linear range of 5.0-65 $\mu \mathrm{g} \mathrm{L}^{-1} \mathrm{As}(\mathrm{V})$ described by the following calibration equation based on 5 different concentrations:

$$
\mathrm{A}=\left(8.94 \times 10^{-4} \pm 1.77 \times 10^{-5}\right) \times C \quad\left(\mathrm{R}^{2}=0.998\right)
$$

404 where $\mathrm{A}$ is the absorbance and $C$ is the $\mathrm{As}(\mathrm{V})$ concentration in $\mu \mathrm{g} \mathrm{\textrm {L } ^ { - 1 }}$.

405 The method repeatability, expressed as the relative standard deviation (RSD) of 5 replicate 406 measurements, was calculated as equal to $1.8 \%$ for $25 \mu \mathrm{g} \mathrm{L}^{-1}$ and $2.8 \%$ for $50 \mu \mathrm{g} \mathrm{L} \mathrm{L}^{-1} \mathrm{As}(\mathrm{V})$, 407 respectively. The limit of detection (LOD) of $3.0 \mu \mathrm{g} \mathrm{\textrm {L } ^ { - 1 }}$ was calculated as the analyte 
concentration corresponding to an analytical signal equal to the blank signal plus three standard

409 deviations of the blank (Miller \& Miller, 2010). The sample solution was propelled for $15 \mathrm{~min}$

410 through the PIM extraction cell while the acceptor solution was stagnant, resulting in a sampling 411 rate of $2.8 \mathrm{~h}^{-1}$.

412 The newly developed FA method provides better sensitivity for the determination of As(V)

413 than other spectrophotometric FA methods (e.g., $51 \mu \mathrm{g} \mathrm{L}^{-1}$ (Boonjob, Miró, \& Kolev, 2013)

414 and $21 \mu \mathrm{g} \mathrm{L}^{-1}$ (Y. Zhang, Miró, \& Kolev, 2015)) and sensitivity comparable to that provided 415 by FA methods utilizing bulky and expensive atomic optical detectors (e.g., atomic 416 fluorescence detector - $0.61 \mu \mathrm{g} \mathrm{L}^{-1}$ (Caballo-Lopez \& Luque de Castro, 2002) and atomic 417 absorption detector $-0.5 \mu \mathrm{g} \mathrm{L}{ }^{-1}$ (Y. Zhang \& Adeloju, 2008).

\subsection{Analysis of drinking water samples}

As mentioned earlier, in most cases arsenic in drinking water consist almost entirely of As(V) (Döker \& Y1lmaz, 2018; Komorowicz \& Barałkiewicz, 2016) and therefore the newly developed method was validated by determining the $\mathrm{As}(\mathrm{V})$ concentration in 4 drinking water samples using the standard addition method (Table 2). The standard addition method was used instead of the calibration curve method because of the high concentrations of common anions relative to the $\mathrm{As}(\mathrm{V})$ concentration. All standard additions curves were characterised by excellent linearity $\left(R^{2} \geq 0.997\right)$ and the repeatability of the slopes of replicate samples $(n=4)$

427 expressed as RSD was 5.6\%. The As concentration in the spiked samples was also determined by HG-ICP-OES using the calibration curve method. There was no statistically significant difference at the $95 \%$ confidence level between the results obtained by both methods (Table 2). 
433 Table 2. As(V) concentration in spiked drinking water samples determined by the newly

434 developed FA method and HG-ICP-OES.

\begin{tabular}{|c|c|c|c|}
\hline \multirow{3}{*}{ Sample } & Spiked As(V) & \multicolumn{2}{|c|}{ Measured $\mathrm{As}(\mathrm{V})$ concentration $\pm \mathrm{SD}$} \\
\hline & concentration & \multicolumn{2}{|c|}{$\left(\mu \mathrm{g} \mathrm{L}^{-1}\right)$} \\
\hline & & FA $(n=3)$ & HG-ICP-OES $(n=3)$ \\
\hline \multirow[t]{3}{*}{ Tap water } & 6.0 & $6.5 \pm 0.5$ & $6.6 \pm 0.4$ \\
\hline & 10.0 & $9.1 \pm 0.7$ & $10.5 \pm 0.8$ \\
\hline & 15.0 & $14.0^{*}$ & $15.8 \pm 0.9$ \\
\hline \multirow[t]{2}{*}{ Voss mineral water } & 6.00 & $5.5 \pm 0.5$ & $6.4 \pm 0.5$ \\
\hline & 10.0 & $10.0^{*}$ & $10.5 \pm 0.4$ \\
\hline \multirow[t]{2}{*}{ Spring mineral water } & 9.00 & $8.3 \pm 0.8$ & $9.4 \pm 0.6$ \\
\hline & 20.0 & $21.0^{*}$ & $21.6 \pm 0.6$ \\
\hline Icelandic mineral & 15.0 & $13.9 \pm 0.9$ & $13.7 \pm 0.5$ \\
\hline water & 25.0 & $22.0^{*}$ & $25.0 \pm 2.0$ \\
\hline
\end{tabular}

436 HG-ICP-OES, hydride generation inductively coupled plasma optical emission spectrometry

\section{Conclusions}

The hydride generation FA system for the determination of arsenate in drinking waters at

440 low $\mu \mathrm{g} \mathrm{L}^{-1}$ levels, developed as part of the current study, utilizes for the first time PIM-based 441 on-line extractive separation of arsenate from the sample matrix which is subsequently reduced 442 to arsine, detected spectrophotometrically after its on-line gas-diffusion separation. Under 443 optimal conditions the FA system is characterized by an LOD of $3.0 \mu \mathrm{g} \mathrm{L} \mathrm{L}^{-1}$ and a repeatability, 444 expressed as RSD, of $1.8 \%\left(n=5,25 \mu \mathrm{g} \mathrm{L}^{-1}\right)$ and $2.8 \%\left(\mathrm{n}=5,50 \mu \mathrm{g} \mathrm{L}^{-1}\right)$. Lower limits of 
445 detection could be potentially achieved by using longer stop-flow times for the extraction step,

446 i.e., larger sample volumes. Common anions, such as phosphate, nitrate, sulphate, carbonate,

447 and chloride, were found to interfere in the PIM-based separation process only at a

448 concentrations 100 times higher than that of arsenate. The newly developed FA system allowed

449 the accurate determination of arsenate in drinking water spiked with $\mathrm{As}(\mathrm{V})$ at the low $\mu \mathrm{g} \mathrm{L}^{-1}$

450 level using the multi-point standard addition method. Since arsenic in most drinking waters is

451 almost entirely composed of arsenate, it can be expected that the FA system, mentioned above,

452 would be applicable for total arsenic determination of drinking water.

453

454 Acknowledgements

455 The financial support of the Spanish government through research project CTM2016456 78798-C2-2-P (AEI/FEDER/UE) is acknowledged. R. Vera acknowledges a grant from 457 Spanish Ministerio de Economía y Competitividad ref. BES-2014-068314. The authors would 458 like to thank the Australian Research Council for financial support of this research (Grant 459 LP100100800). 
Almeida, M. I. G. S., Cattrall, R. W., \& Kolev, S. D. (2012). Recent trends in extraction and transport of metal ions using polymer inclusion membranes (PIMs). Journal of Membrane Science, 415-416, 9-23.

Almeida, M. I. G. S., Cattrall, R. W., \& Kolev, S. D. (2017). Polymer inclusion membranes (PIMs) in chemical analysis - A review. Analytica Chimica Acta, 987, 1-14.

Alves, V. N., Neri, T. S., Borges, S. S. O., Carvalho, D. C., \& Coelho, N. M. M. (2017). Determination of inorganic arsenic in natural waters after selective extraction using Moringa oleífera seeds. Ecological Engineering, 106, 431-435.

Bissen, M., \& Frimmel, F. H. (2003). Arsenic - A review. Part I: Occurrence, toxicity, speciation, mobility. Acta Hydrochimica et Hydrobiologica, 31(1), 9-18.

Boonjob, W., Miró, M., \& Kolev, S. D. (2013). On-line speciation analysis of inorganic arsenic in complex environmental aqueous samples by pervaporation sequential injection analysis. Talanta, 117, 8-13.

Caballo-Lopez, A., \& Luque de Castro, M. D. (2002). Hydride generation-pervaporationatomic fluorescence detection prior to speciation analysis of arsenic in dirty samples. Journal of Analytical Atomic Spectrometry, 17(10), 1363-1367.

Cerda, V., \& Estela, J. M. (2008). On-line sample pretreatment: dissolution and digestion. In S. D. Kolev \& I. D. McKelvie (Eds.), Advances in Flow Injection Analysis and Related Techniques 1 ed., (pp. 129-158). Amsterdam: Elsevier.

Chen, G., Lai, B., Mao, X., Chen, T., \& Chen, M. (2017). Continuous Arsine Detection Using a Peltier-Effect Cryogenic Trap to Selectively Trap Methylated Arsines. Analytical Chemistry, 89(17), 8678-8682.

Cho, Y., Xu, C., Cattrall, R. W., \& Kolev, S. D. (2011). A polymer inclusion membrane for extracting thiocyanate from weakly alkaline solutions. Journal of Membrane Science, 367(1), 85-90.

Dhar, R. K., Zheng, Y., Rubenstone, J., \& Van Geen, A. (2004). A rapid colorimetric method for measuring arsenic concentrations in groundwater. Analytica Chimica Acta, 526(2), 203-209.

Döker, S., \& Y1lmaz, M. (2018). Speciation of Arsenic in Spring, Well, and Tap Water by Highperformance Liquid Chromatography-Inductively Coupled Plasma-Mass Spectrometry. Analytical Letters, 51(1-2), 254-264.

Farrell, J. R., Iles, P. J., \& Yuan, Y. J. (1996). Determination of arsenic by hydride generation gas diffusion flow injection analysis with electrochemical detection. Analytica Chimica Acta, 334(1-2), 193-197.

Fogg, A. G., \& Bsebsu, N. K. (1981). Differential-pulse voltammetric determination of phosphate as molybdovanadophosphate at a glassy carbon electrode and assessment of eluents for the flow injection voltammetric determination of phosphate, silicate, arsenate and germanate. Analyst, 106(1269), 1288-1295.

Fontàs, C., Vera, R., Batalla, A., Kolev, S. D., \& Anticó, E. (2013). A novel low-cost detection method for screening of arsenic in groundwater. Environmental Science and Pollution Research, 21(20), 11682-11688.

Frenzel, W., Titzenthaler, F., \& Elbel, S. (1994). Selective determination of arsenite by flow injection spectrophotometry. Talanta, 41(11), 1965-1971.

Güell, R., Anticó, E., Kolev, S. D., Benavente, J., Salvadó, V., \& Fontàs, C. (2011). Development and characterization of polymer inclusion membranes for the separation and speciation of inorganic As species. Journal of Membrane Science, 383(1-2), 88-95. 
Güell, R., Fontàs, C., Anticó, E., Salvadó, V., Crespo, J. G., \& Velizarov, S. (2011). Transport and separation of arsenate and arsenite from aqueous media by supported liquid and anion-exchange membranes. Separation and Purification Technology, 80(3), 428-434.

Johnson, D. L., \& Pilson, M. E. Q. (1972). Spectrophotometric determination of arsenite, arsenate, and phosphate in natural waters. Analytica Chimica Acta, 58(2), 289-299.

Kamyabi, M. A., \& Aghaei, A. (2016). Electromembrane extraction and spectrophotometric determination of $\mathrm{As}(\mathrm{V})$ in water samples. Food Chemistry, 212, 65-71.

Komorowicz, I., \& Barałkiewicz, D. (2016). Determination of total arsenic and arsenic species in drinking water, surface water, wastewater, and snow from Wielkopolska, KujawyPomerania, and Lower Silesia provinces, Poland. Environmental Monitoring and Assessment, 188(9), 504.

Lomonte, C., Currell, M., Morrison, R. J. S., McKelvie, I. D., \& Kolev, S. D. (2007). Sensitive and ultra-fast determination of arsenic(III) by gas-diffusion flow injection analysis with chemiluminescence detection. Analytica Chimica Acta, 583(1), 72-77.

Miller, J. C., \& Miller, J. N. (2010). Statistics and chemometrics for Analytical Chemistry. Harlow, Essex England: Pearson Education Limited.

Nagul, E. A., Fontàs, C., McKelvie, I. D., Cattrall, R. W., \& Kolev, S. D. (2013). The use of a polymer inclusion membrane for separation and preconcentration of orthophosphate in flow analysis. Analytica Chimica Acta, 803, 82-90.

Narusawa, Y. (1988). Flow-injection spectrophotometric determination of silicate, phosphate and arsenate with on-line column separation. Analytica Chimica Acta, 204, 53-62.

Nghiem, L. D., Mornane, P., Potter, I. D., Perera, J. M., Cattrall, R. W., \& Kolev, S. D. (2006). Extraction and transport of metal ions and small organic compounds using polymer inclusion membranes (PIMs). Journal of Membrane Science, 281(1), 7-41.

O'Bryan, Y., Cattrall, R. W., Truong, Y. B., Kyratzis, I. L., \& Kolev, S. D. (2016). The use of poly(vinylidenefluoride-co-hexafluoropropylene) for the preparation of polymer inclusion membranes. Application to the extraction of thiocyanate. Journal of Membrane Science, 510, 481-488.

Rupasinghe, T., Cardwell, T. J., Cattrall, R. W., \& Kolev, S. D. (2009). Determination of arsenic in industrial samples by pervaporation flow injection with amperometric detection. Analytica Chimica Acta, 652(1-2), 266-271.

Rupasinghe, T., Cardwell, T. J., Cattrall, R. W., Luque de Castro, M. D., \& Kolev, S. D. (2001). Pervaporation-flow injection determination of arsenic based on hydride generation and the molybdenum blue reaction. Analytica Chimica Acta, 445(2), 229-238.

Rupasinghe, T., Cardwell, T. J., Cattrall, R. W., Potter, I. D., \& Kolev, S. D. (2004). Determination of arsenic by pervaporation-flow injection hydride generation and permanganate spectrophotometric detection. Analytica Chimica Acta, 510(2), 225-230.

Susko, M. L., Bloom, M. S., Neamtiu, I. A., Appleton, A. A., Surdu, S., Pop, C., Fitzgerald, E. F., Anastasiu, D., \& Gurzau, E. S. (2017). Low-level arsenic exposure via drinking water consumption and female fecundity - A preliminary investigation. Environmental Research, 154(October 2016), 120-125.

Toda, K., \& Ohba, T. (2005). Highly Sensitive Flow Analysis of Trace Level Arsenic in Water Based on Vaporization-collection In-line Preconcentration. Chemistry Letters, 34(2), 176-177.

Valcarcel, M., \& Luque de Castro, M. D. (1987). Flow-Injection Analysis: Principles and Applications. Chichester: Ellis Horwood.

Vera, R., Fontas, C., \& Antico, E. (2017). Titanium dioxide solid phase for inorganic species adsorption and determination: the case of arsenic. Environmental Science and Pollution Research, 24(12), 10939-10948. 
Villaescusa, I., \& Bollinger, J.-C. (2008). Arsenic in drinking water: sources, occurrence and health effects (a review). Reviews in Environmental Science and Bio/Technology, 7(4), 307-323.

WHO. (2011). Guidelines for drinking-water quality, 4th edition (4th ed.): World Health Organization (WHO)

Yaftian, M. R., Almeida, M. I. G. S., Cattrall, R. W., \& Kolev, S. D. (2018). Flow injection spectrophotometric determination of $\mathrm{V}(\mathrm{V})$ involving on-line separation using a poly(vinylidene fluoride-co-hexafluoropropylene)-based polymer inclusion membrane. Talanta, 181(November 2017), 385-391.

Zhang, L. L., Cattrall, R. W., Ashokkumar, M., \& Kolev, S. D. (2012). On-line extractive separation in flow injection analysis based on polymer inclusion membranes : A study on membrane stability and approaches for improving membrane permeability. Talanta, 97, 382-387.

Zhang, L. L., Cattrall, R. W., \& Kolev, S. D. (2011). The use of a polymer inclusion membrane in flow injection analysis for the on-line separation and determination of zinc. Talanta, 84(5), 1278-1283.

Zhang, Y., \& Adeloju, S. B. (2008). Flow injection-hydride generation atomic absorption spectrometric determination of selenium, arsenic and bismuth. Talanta, 76(4), 724-730.

Zhang, Y., Miró, M., \& Kolev, S. D. (2015). Hybrid flow system for automatic dynamic fractionation and speciation of inorganic arsenic in environmental solids. Environmental Science and Technology, 49(5), 2733-2740. 